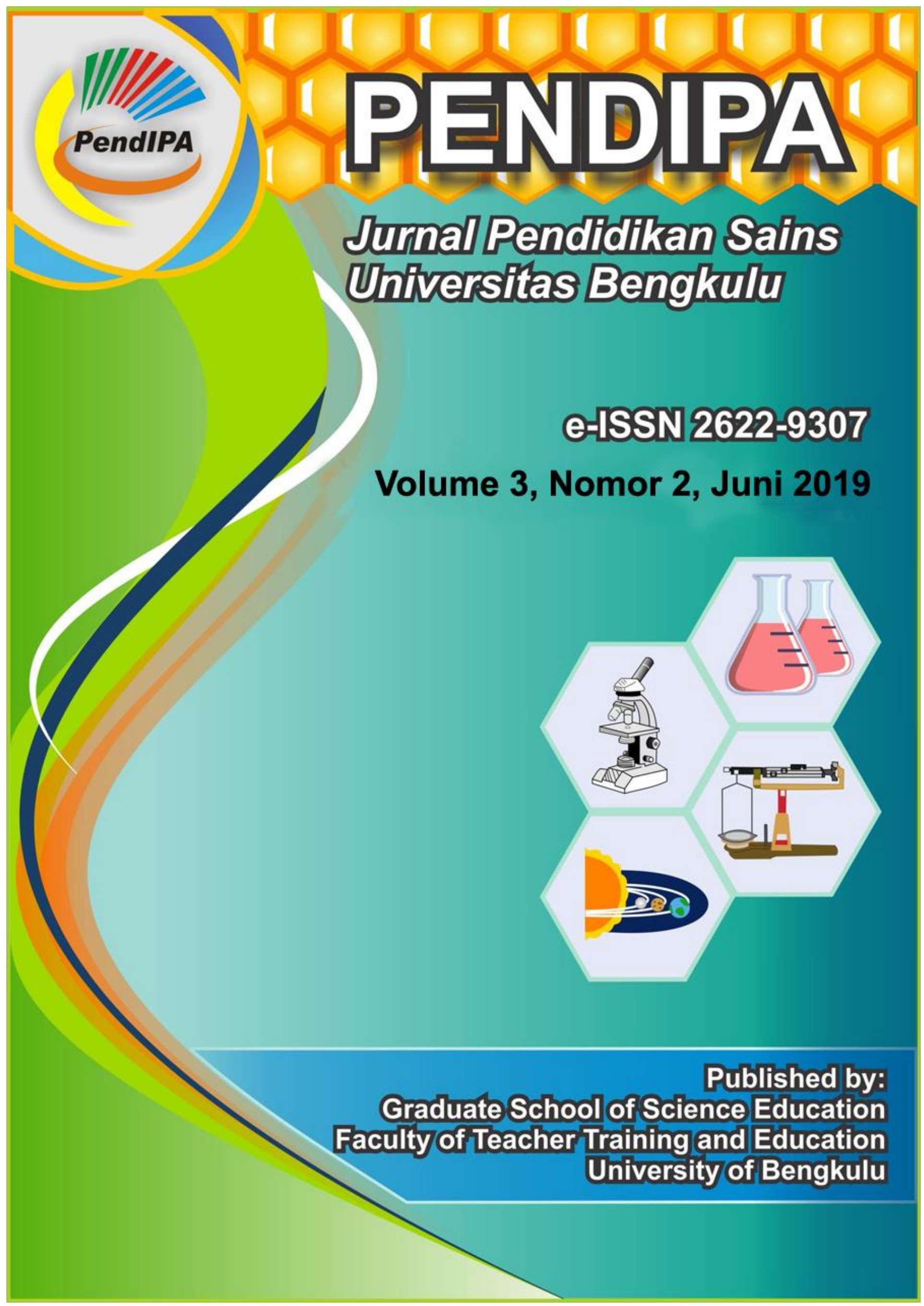




\section{PENDIPA Journal of Science Education}

e-ISSN 2622-9307

Volume 3, Nomor 2, Juni 2019

\begin{abstract}
About
PENDIPA Journal of Science Education is a peerreviewed, open-access journal covered all aspect of science and science education. PENDIPA journal welcomes the submission of scientific articles related to mathematics, physics, chemistry, biology, and its implementation in a school, higher education and other educational institution. We encourage scientist, lecturer, teacher and student to submit their original paper to the journal. PENDIPA journal is published by Graduate School of Science Education University of Bengkulu, three times a year on February, June and October.
\end{abstract}

\section{Editor-in-Chief}

M. Lutfi Firdaus, University of Bengkulu

\section{Associate Editors \\ Agus Sundaryono, University of Bengkulu, Aceng Ruyani, University of Bengkulu Afrizal Mayub, University of Bengkulu Bhakti Karyadi, University of Bengkulu, Sumpono, University of Bengkulu}

\section{Journal Manager}

Annisa Puji Astuti, University of Bengkulu

\section{Technical Support}

Bambang Gonggo Murcitro, University of Bengkulu

\section{International Advisory Boards}

Prof. Dr. Hajime Obata, The University of Tokyo Prof. Aldes Lesbani Ph.D, Sriwijaya University Dr. Renat Khaydarov, Inst. Nuclear Phys., Uzbekistan Dr. Mohammad Basyuni, Univ. of Sumatera Utara Dr. Diana Rakhmawaty E, Universitas Padjadjaran Dr. Dodi Devianto, Andalas University, Indonesia Dr. Rahmat Hidayat, Bogor Agricultural University Dr. Acep Purqon, Bandung Insitute of Technology Dr. Santhy Wyantuti, Universitas Padjadjaran Dr. Yeni W. Hartati, Universitas Padjadjaran Dr. Abigail Cid-Andres, Polytech. Univ. Philippines Dr. Taejin Kim, Seoul National University Dr. Asami S. Mashio, Kanazawa University

\section{Kata Pengantar}

Pembaca Jurnal PENDIPA yang berbahagia, Puji syukur kami panjatkan kehadirat Allah SWT, karena atas berkat dan rahmatNya lah kami dapat kembali hadir menyapa para pembaca untuk menyajikan artikel-artikel terbaru yang terbit pada Jurnal PENDIPA Volume 3, Nomor13, Edisi Februari 2019 ini. Seluruh artikel yang dimuat pada Jurnal PendIPA ini telah melewati proses seleksi dan telah ditelaah oleh Dewan Editor dan Mitra Bestari yang kompeten di bidangnya masing-masing. Hanya artikel-artikel berkualitas baik yang dapat dimuat pada Jurnal PENDIPA.

Topik-topik yang disajikan pada edisi kali ini meliputi: model pembelajaran problem solving dan discovery learning, aklimasi kura-kura, pengembangan modul, pembelajaran berbasis lingkungan dan discovery learning, peningkatan kemampuan berpikir kreatif dan kritis siswa, serta identifikasi jenis-jenis herpetofauna.

Kepada seluruh penulis dan mitra bestari yang telah berkontribusi pada terbitan edisi Juni 2019 ini, kami menyampaikan banyak terima kasih. Kami juga mengundang seluruh rekan sejawat, peneliti, dosen, guru dan mahasiswa di bidang pendidikan sains, matematika, fisika, kimia dan biologi untuk berkontribusi dan mengirimkan naskahnya ke jurnal PENDIPA. Akhir kata, seperti kata pepatah "Tiada gading yang tak retak", maka saran dan kritik yang membangun dari semua pihak selalu kami harapkan.

\section{Ketua Dewan Redaksi,}

\section{Lutfi Firdaus}

PENDIPA Journal is indexed by CrossRef, Google Scholar, PKP Index, Academia.edu, Mendeley, etc. Subscription costs: Rp. 0,- (Free to download) Publication costs: Rp. 300.000,- (To be paid after acceptance of the manuscript).

\footnotetext{
Publisher

Graduate School of Science Education, University of Bengkulu Jl. WR Supratman, Bengkulu 38371 https://ejournal.unib.ac.id/index.php/pendipa Email: pascapendipa@unib.ac.id
} 


\section{DAFTAR ISI}

Halaman Sampul. i

Susunan Redaksi dan Kata Pengantar ii

Daftar Isi iii

Penerapan Model Pembelajaran Problem Solving Fisika pada Konsep Listrik Dinamis Di SMA IT IQRA Kota Bengkulu

Fitri Nur Khairi, Muhammad Farid, Eko Swistoro

Implementasi Model Discovery Learning Pada Materi Aplikasi Gelombang Elektromagnetik Analisis Pengotor Berbagai Minyak Goreng Sawit dengan Spektrofotometri UV-Vis

Tria Wulandari, Nirwana Nirwana, M. Lutfi Firdaus

Aklimasi Notochelys platynota yang akan dilepas di area target konservasi kura-kura Universitas Bengkulu

Rica Yuniar Tanjung, Aceng Ruyani

Pengembangan Modul Berbasis Penelitian Pencegahan P. berghei pada Mus musculus terhadap Berpikir Kritis Mahasiswa

Maya Wahyunarti, Ridwan Yahya, Agus Sundaryono

Kemampuan Pemecahan Masalah pada Siswa Kelas X MA Suka Negeri Begkulu Selatan Melalui Pembelajaran Berbasis Lingkungan

Roni Sastiawan, Aceng Ruyani, Bhakti Karyadi... 84-89

Implementasi Pembelajaran Discovery Learning pada Materi Temperatur, Tekanan dan Energi untuk Meningkatkan Pembelajaran Fisika di SMA Kelas X

Pedro Aldriner Sihite, Muhammad Farid, Afrizal Mayub

Pengembangan Modul KOBA dengan Model 4-D untuk Meningkatkan Kemampuan Berpikir Kreatif Mahasiswa

Suryadi Suryadi, Agus Sundaryono, Nurhamidah Nurhamidah

Kemampuan Berpikir Kritis Siswa Melalui Pembelajaran Berbasis Lingkungan untuk Studi Ekosistem Sungai

Fema Anggriani, Bhakti Karyadi, Aceng Ruyani

100-105

Identifikasi Jenis-jenis Herpetofauna di Taman Wisata Alam Gunung Permisan, Bangka Selatan, Provinsi Kepulauan Bangka Belitung

Riko Irwanto, Rahmad Lingga, Rama Pratama, Salsa Annada Ifafah.... 106-113 